\title{
Editorial: Branding in store - Marketing in the 21st century
}

'We have only two moments of truth when the consumer is in store at the point of purchase; and when she is at home using the product. ${ }^{1}$

Chris Lapuente - Vice President and Managing Director, Procter \& Gamble

When the brand giant Procter \& Gamble makes such a strong statement, the marketing community would do well to listen.

The growth of retailers' power in the last 20 years has become a phenomenon we have all grown used to. Has the marketing community woken up to what it means and changed well-established habits, however?

Working with the retailer is not just about negotiating the best possible price and surviving on reduced margins. The successful brands have evolved ways of making brand statements and presence in store a key part of the marketing mix. Cleverly used, in-store presentation has grown from being one of the minor aspects of a brand campaign into being a crucial part of the communication to consumers.

Traditionally, working directly with the retailer has been the responsibility of the sales function. More recently trade marketing departments have grown up to take responsibility for developing brand imagery and supporting retailers. This adds to the well being of the brand, as well as meeting the stringent and varied requirements of retailers.

\section{THE GROWTH OF THE POWER OF RETAILERS}

Statistics abound giving examples of the power of retailers, including:

- Globally, Walmart takes 17 per cent of all the sales of Procter \& Gamble, and this is estimated to grow to over 20 per cent by 2008 . This gives enormous influence to one retailer.

- Within the UK, 85 per cent of paint sales are concentrated through three named outlet groups.

Retailers worldwide are not only aware of their growing power, but flex their muscles and squeeze the margins regularly. Brands respond to this pressure in a variety of ways. Leading the charge is in-store marketing and display, the method of presentation of the product to the consumer inside the store.

Research by the Point of Purchase Advertising Institute (POPAI) ${ }^{2}$ over many years has consistently shown that up to 75 per cent of purchasing decisions are made in store. Consumers have a profile of brands that they will consider purchasing, and the choice of which one to buy is made at the moment of brand selection inside the store. Tim Mason, marketing director at Tesco, refers to this as targeting potential customers at the moment they are concentrating on retail selection. ${ }^{3}$ More people use a Tesco loyalty card than watch the average episode of Coronation Street. This is a 
marketing opportunity, not a threat. It marks a change in the medium used to communicate with customers.

The golden age of consumer branding on television was the 1950s and $60 \mathrm{~s}$, when the miracle of commercial television allowed brands to drum their message into the minds of consumers, creating mass markets that they more or less owned. That worked well for as long as people watched the same commercials and bought the same products. But today there are hundreds of channels to choose from and people are much more individualistic in their tastes, so brand owners are left trying to sell to a mass market that does not exist in the same form.

Consumer choice is fragmenting too. As Richard Hyman of Verdict Research has pointed out, consumers do not just want lots of choice, they want offers that have been formulated for them individually. ${ }^{4}$ What they really want is edited choice. The old sea-ofmerchandise approach has long gone. By providing edited choice, retailers can develop brand loyalty, and it enables point-of-purchase display to come into its own.

Display helps emphasise the retailer's choice and discernment to the consumer. By making a brand stand out to consumers in store, and at the moment they are about to make their brand choice and purchase, display is marketing pure and direct.

Display has the great merit of being an avenue that has traditionally received underinvestment. Generally, a Euro well spent in display will offer more return than a Euro well spent in most other parts of the marketing mix because, in the past, it has received less attention than other areas.

Point-of-purchase display raises awareness among consumers and stimulates the desire to buy, but also encourages consumers to touch, pick up and look at the product.

Of equal attraction to the retailer is the ability of display to increase the efficiency of store staff and reduce the occurrence of out-of-stock items, particularly leading lines. Colour cosmetics offer a good example. For leading stock-keeping units (SKUs) the most popular colours are, by definition, the most often bought. Staff need to be helped to keep the brand offer well merchandised and available to the consumer, to maximise sales for everyone's benefit. Good merchandising and display helps the brand stand out, helps the staff keep the stock on the shelf, not at the back of the shop, and helps the consumer find their desired product.

Well-engineered displays can be tailored to the size and style demanded by each individual retailer, creating a personalised offer, while at the same time presenting a consistent image to the consumer and reusing investment in both design and tooling.

\section{BRAND COMMUNICATION}

As any good brand manager will state, communicating consistently with the consumer is the key to maximising the effectiveness of the message. Carrying the message from outside the store and above the line through to inside will always create maximum impact. Display is three-dimensional marketing. In fact, with the exception of packaging, it is the only dimensional part of marketing. The rest is a concept, a design, a position.

The aim of using the display, along with the rest of the marketing mix, is 


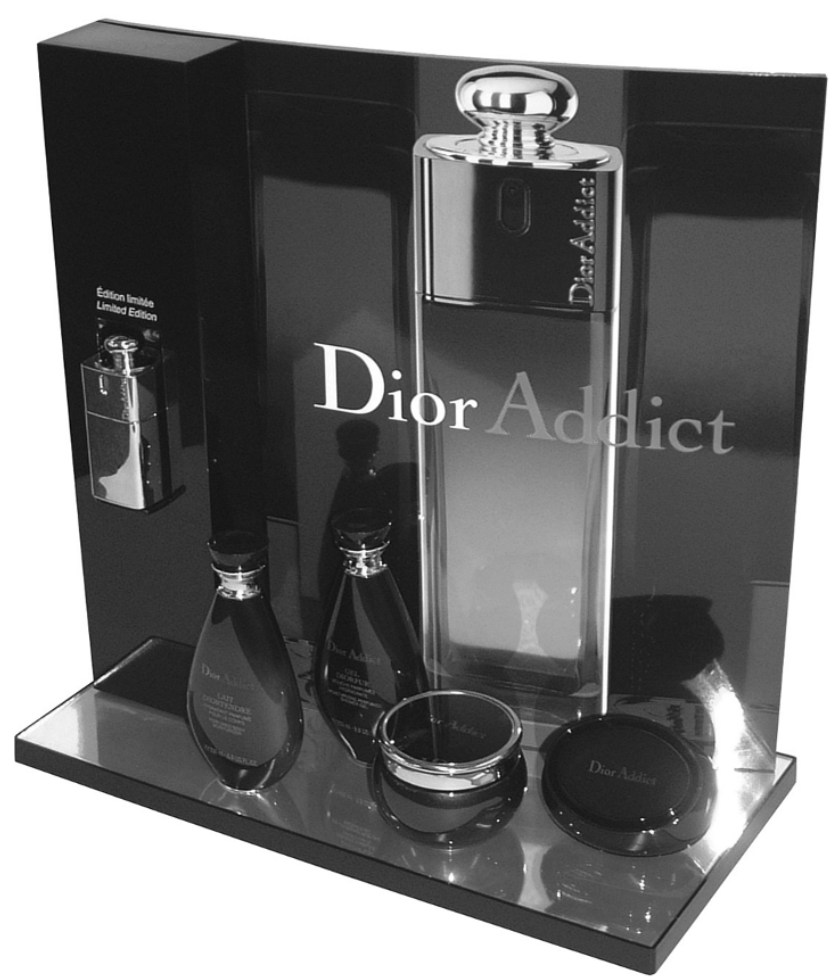

Figure I The Christian Dior product

to get to a point where the total is greater than the sum of the constituent parts. That is to say, the message is consistently repeated across all mediums, creating benefits.

\section{BRAND EXAMPLES OF GLOBAL MERCHANDISING}

Take as an example Christian Dior (see Figure 1). Dior has become the global leader in a highly competitive environment. It has achieved its position by consistently presenting the product to maximum effect, so that wherever the consumer makes a purchase, whether in Paris, London or anywhere else in the world, the Dior blue will be a constant presence. A style and colour has been developed so that, despite all the competing noise and distractions of a busy cosmetics counter, the consumer will recognise the Dior image from a distance and feel attracted and comforted by its consistency. Kesslers has worked with Dior on this for many years and has coined the phrase 'brand intensification'.

Brand intensification is all about making the brand stand out and creating maximum impact, for the same budget. It is about being consistent to the consumer yet working with the retailer in meeting their particular needs. The great brands do it. The role of display is to maximise - or, to use the jargon, intensify - the impact of the brand.

Consistent use of logos across all points of the marketing compass has become well established. Think only of the uproar caused at many a presentation when an old logo, or one that breaks the brand guidebook, is 
presented to the assembled masses. The same touching faith should be put into consistent presentation in store.

\section{THE FUTURE IS HERE NOW}

Working to support the brands in store has rapidly become a key responsibility of brand managers. The process of supporting brands in store addresses not just the power of the retailer, but also their need to increase sales and return on investment, without resorting to challenging margins for the product. It gives communication power at a time when traditional above-the-line mediums are declining. It is communication without language, crossing international boundaries in a way other marketing campaigns cannot. It gives familiarity to the consumer in their wider net of brand purchasing, wherever they may be in the world.

In-store display works amazingly well with that other newcomer to the marketing fraternity — internet shopping. Research on internet shopping profiles consistently shows that one of the major attractions of the retail environment to the consumer is the ability to see and touch the product in store. ${ }^{5}$ The internet has prepared the consumer to be ever more alert for information and back-up support to inform brand choices. Displays in store give that medium the opportunity for expression.

\section{THE WAY FORWARD}

All the marketing signals point to the following in store:
- A demographic profile of ageing consumers who are time rich, money poor, and therefore have more time to spend in store - that is where their brand choices will be made.

- Retailers who are making their offer stand out; that is where decisions on which brands to list will be taken.

- Consumers who want to be helped to find the right product, and want to be informed of its brand characteristics; who benefit from being reminded of the marketing position and image of their favourite brand. They look to make their choice in store.

In-store marketing and display has arrived in a big way. It has risen greatly up the list of brand requirements, with its own advantages and special demands. In-store brand choice is the point at which the consumer finally makes that brand decision, and the successful brands follow that through for maximum impact.

\section{References}

(1) (2002) Sunday Times, August.

(2) Mason, T. (2002) 'Right place, right time', FT Creative Business, 26th November.

(3) Ibid.

(4) Hyman, R. (2002) 'The retail roller-coaster: Message from the High Street', Market Leader, Summer.

(5) (2002) 'Consumer Shopping Habits Survey', MORI/Kesslers International. 